\title{
Does team lifting increase the variability in peak lumbar compression in ironworkers?
}

\author{
Gert Faber $^{* a, b, c}$, Steven Visser ${ }^{\mathrm{d}}$, Henk F. van der Molen ${ }^{\mathrm{d}, \mathrm{e}}$, P. Paul F.M. Kuijer ${ }^{\mathrm{d}}$, Marco J.M. Hoozeman- \\ $\mathrm{s}^{\mathrm{a}, \mathrm{f}}$, Jaap H. van Dieën ${ }^{\mathrm{a}}$, Monique H.W. Frings-Dresen ${ }^{\mathrm{d}}$ \\ ${ }^{a}$ Research Institute MOVE, Faculty of Human Movement Sciences, VU University, Van der Boechorststraat 9 , \\ 1081 BT, Amsterdam, The Netherlands \\ ${ }^{b}$ Department of Environmental Health, Harvard School of Public Health, 665 Huntington Avenue, Boston, MA \\ 02115, USA \\ ${ }^{c}$ Liberty Mutual Research Institute for Safety, 71 Frankland Road, Hopkinton, MA 01748, USA \\ ${ }^{d}$ Coronel Institute of Occupational Health, Academic Medical Center, University of Amsterdam, PO Box 22700, \\ 1100 DE Amsterdam, the Netherlands \\ 'Arbouw, Ceintuurbaan 2, 3847 LG Harderwijk, the Netherlands \\ ${ }^{f}$ EXPres, Faculty of Human Movement Sciences, VU University, Van der Boechorststraat 9 , \\ 1081 BT, Amsterdam, The Netherlands
}

\begin{abstract}
Ironworkers frequently perform heavy lifting tasks in teams of two or four workers. Team lifting could potentially lead to a higher variation in peak lumbar compression forces than lifts performed by one worker, resulting in higher maximal peak lumbar compression forces. This study compared single-worker lifts (25-kg, iron bar) to two-worker lifts (50-kg, two iron bars) and to four-worker lifts (100-kg, iron lattice). Inverse dynamics was used to calculate peak lumbar compression forces. To assess the variability in peak lumbar loading, all three lifting tasks were performed six times. Results showed that the variability in peak lumbar loading was somewhat higher in the team lifts compared to the single-worker lifts. However, despite this increased variability, team lifts did not result in larger maximum peak lumbar compression forces. Therefore, it was concluded that, from a biomechanical point of view, team lifting does not result in an additional risk for low back complaints in ironworkers.
\end{abstract}

Keywords: team lifting, spinal loading, occupational biomechanics, low back pain/injury, construction work

\section{Introduction}

Low back injuries are very common among construction workers [1]. This is probably due to high mechanical loading of the spine involved in tasks frequently performed during work such as manual lifting [2].

In the Netherlands, ironworkers lift loads up to $100 \mathrm{~kg}$. When a load is lifted by one worker, loads up to $25-\mathrm{kg}$ are allowed by the Dutch labor inspectorate. Consequently, a $50-\mathrm{kg}$ load should be lifted by two workers and a 100-kg load by four workers. Although the average mass lifted by each worker is the same in all three kinds of lifts, one could expect that lifts with multiple workers (team lifting) result in a more variable peak lumbar loading (i.e. higher maximum peak lumbar loading), because the distribution of the mass over the workers in team lifting depends on the timing and speed of the lifting motion of each worker.

The objective of the current study was to investigate if the within-subject variability in peak lumbar loading was higher during team lifting compared to lifts performed by a single person.

\footnotetext{
${ }^{*}$ Corresponding author. E-mail: gertfaber.sci@gmail.com, Tel no.: +1-617-384-8768
} 


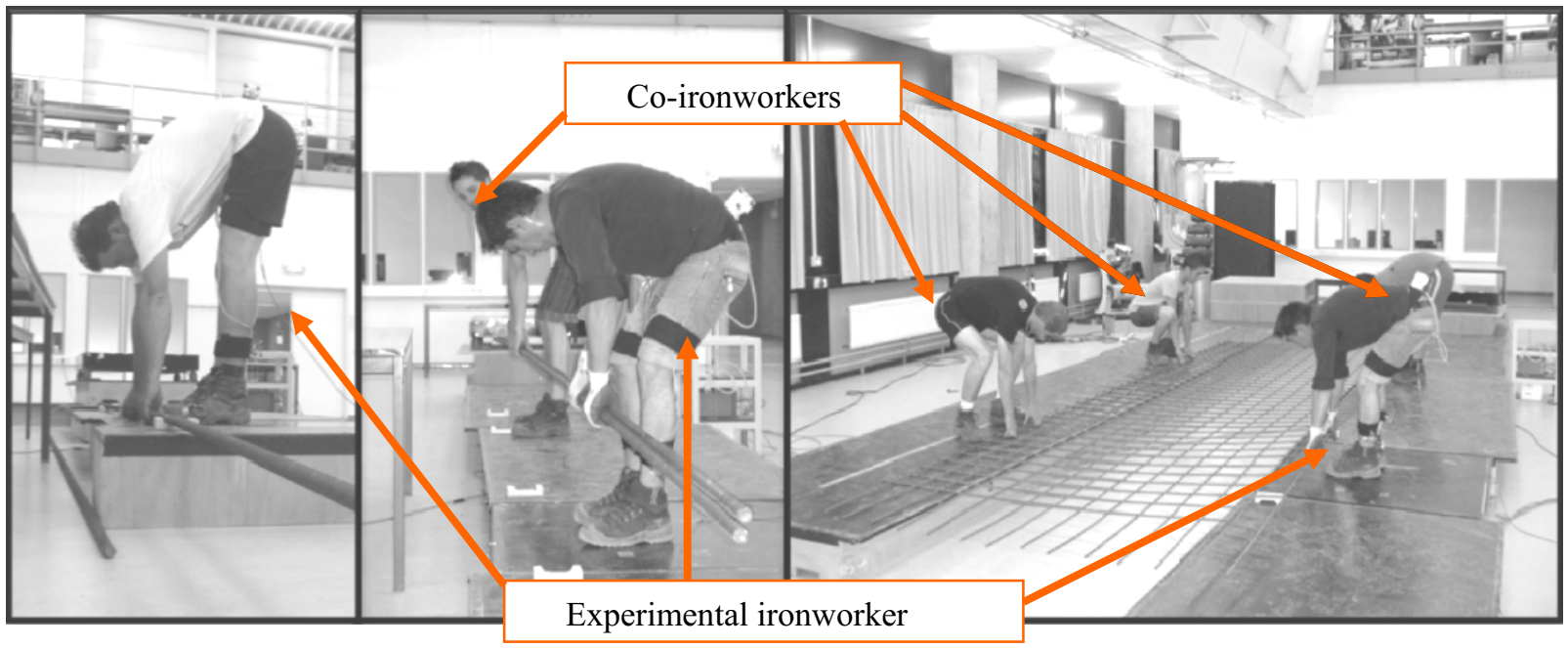

Fig. 1. Left: single-worker lift (25kg), Middle: two-worker team lift (50kg), Right: four-worker team lift (100kg)

\section{Method}

\subsection{Subjects}

Before participating in the present biomechanical laboratory experiment, all ironworkers signed an informed consent. Due to the limited measurement volume, the biomechanical loading could only be assessed for one ironworker at a time. For each ironworker that was measured (experimental ironworker), three others participated in the team lifts during the experiment (co-ironworker). In total, ten experimental ironworkers participated in the study: mean (SD) age, stature, weight and years of work experience were $31(8)$ years, $180(8) \mathrm{cm}, 80(13) \mathrm{kg}$ and 11 (9) years, respectively.

\subsection{Lifting tasks}

The ironworkers performed three lifting tasks that are frequently observed at the workplace (Figure 1):

1 lifting a $25-\mathrm{kg}$ load, one iron bar, alone (singleworker lift),

2 lifting a 50-kg load, two iron bars, in a team with one other ironworker (two-worker lift),

3 lifting a $100-\mathrm{kg}$ load, an iron lattice, in a team with 3 other ironworkers (four-worker lift).

To be able to assess the within-subject variability in peak lumbar loading, all three lifting tasks were performed six times by each experimental ironworker. For the two-worker lifts, the experimental ironworker performed two team lifts together with each of the three co-ironworkers (six lifts total). For the fourworker lifts, the experimental ironworker performed six lifts in a team together with all three coironworkers. Between trials, co-ironworkers rotated position such that each co-ironworker lifted the iron lattice two times at the opposite diagonal corner with respect to the experimental ironworker.

\subsection{Biomechanical analysis}

Lower-body kinematics, ground reaction forces and anthropometrics were measured and used in a 3D inverse dynamics model [3] to calculate lumbar moments. Subsequently, based on these lumbar moments, the peak lumbar compression forces was calculated for each lift using regression equations reported by van Dieën \& Kingma [4].

\subsection{Statistics}

For each task performed by each individual worker (six lifts), the mean peak lumbar compression force, the within-subject variability in peak lumbar compression force (standard deviation over the six lifts) and the maximum peak lumbar compression force was calculated. Significance of the differences between the single-worker lifts and each of the team lifts (two-worker and four-worker) were tested with paired t-tests.

\section{Results}

Comparable mean peak lumbar compression forces were found for the single-worker and twoworker lifts, while lower mean peak lumbar compression forces (about $8 \%$ ) were found for the fourworker lifts (Figure 2, left). The team lifts resulted in a somewhat higher variation in peak lumbar compression (only significant for two-worker lifts). (Fig- 
ure 2, centre). However, the effect was small and did not result in the maximum peak compression forces to become higher in the team lifts compared to the single-worker lifts (Figure 2, right).

\section{Discussion}

In line with previous research [5, 6], the current study found lower mean lumbar compression forces in the team lifts in which the workers were facing each other (four-worker lifts). This is probably because ironworkers exerted horizontal forces towards the body in this condition, resulting in moments counteracting the lumbar extension moment. In the single- and two-worker lifts this was not feasible because in this condition there was no co-worker present that could counteract these horizontal forces. Therefore, it is not surprising that the single- and two-worker lifts resulted in comparable mean peak lumbar loading [7]. With respect to the variability in peak lumbar compression forces, we indeed found more variability in the team lifts compared to the single-worker lifts (only significant for the twoworker lift). However, despite this increased variabil- ity, team lifts did not result in larger maximum peak lumbar compression forces.

In conclusion, from a biomechanical point of view, team lifting does not result in an additional risk for low back complaints in ironworkers.

\section{References}

[1] Holmström E \& Engholm G. Musculoskeletal disorders in relation to age and occupation in Swedish construction workers. Am. J. Ind. Med. (2003), 44(4), 377-384.

[2] da Costa BR \& Vieira ER. Risk factors for work-related musculoskeletal disorders: A systematic review of recent longitudinal studies. Am. J. Ind. Med. (2010), 53(3), 285-323.

[3] Kingma I, de Looze MP, Toussaint HM, Klijnsma HG \& Bruijnen TBM. Validation of a full body 3-D dynamic linked segment model. Hum. Mov. Sci. (1996), 15(6), 833-860.

[4] van Dieën JH \& Kingma I. Effects of antagonistic cocontraction on differences between electromyogra-phy based and optimization based estimates of spinal forces. Ergonomics (2005), 48(4), 411-26.

[5] Dennis GJ \& Barrett RS. Spinal loads during individual and team lifting. Ergonomics (2002), 45(10): 671-681.

[6] Marras WS, Davis KG, Kirking BC \& Granata KP. Spine loading and trunk kinematics during team lift-ing. Ergonomics (1999), 42(10), 1258-1273.

[7] van der Molen HF, Visser S, Kuijer PPFM, Faber GS, Hoozemans MJM, van Dieën JH, Frings-Dresen MHW. The evaluation of team lifting on physical work demands and workload in ironworkers. This proceedings.
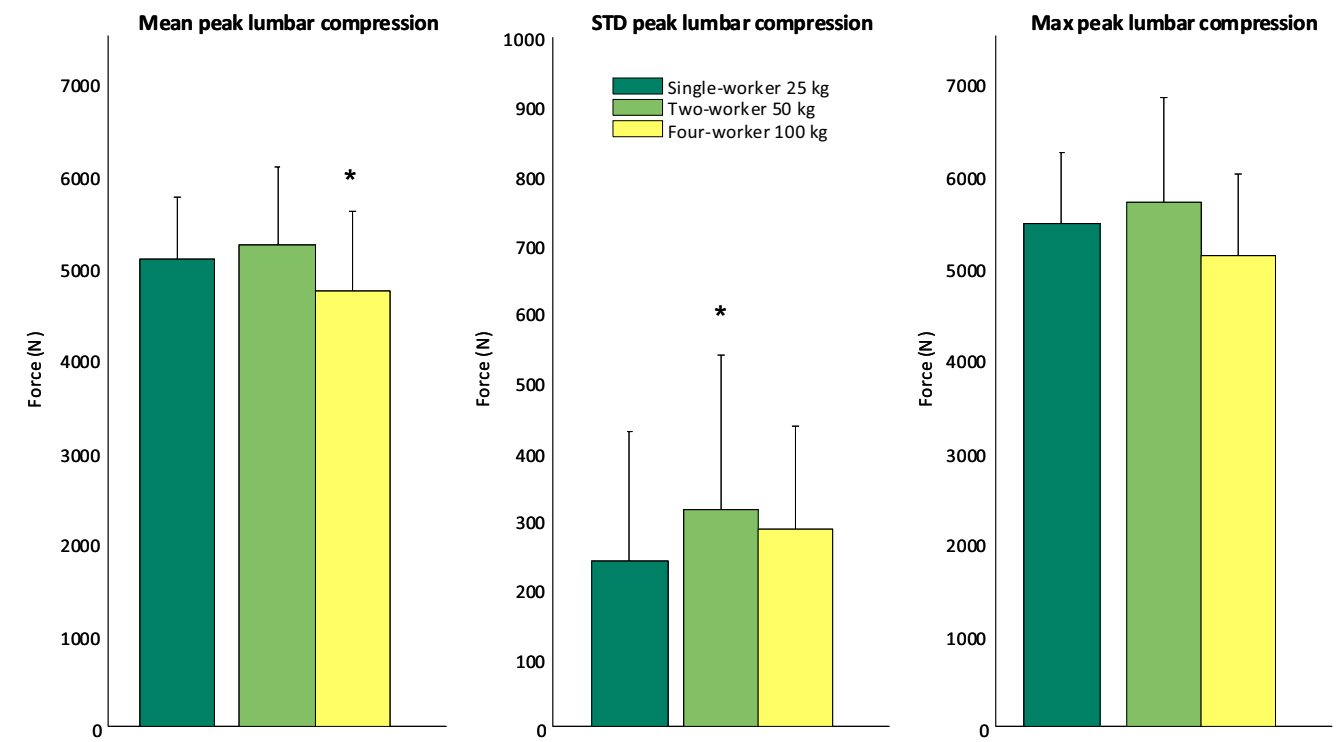

Fig 2. Effect of team lifting on mean peak lumbar compression (left), variation in peak lumbar compression (centre) and maximal peak lumbar compression (right). * indicate significant differences between the single-worker lifts and the team lifts (two-worker, four worker). 